\title{
PODER, POLÍTICA E TRADUÇÃO: NOTAS PARA UMA GENEALOGIA DO PENSAMENTO FREIREANO NO EXTERIOR
}

\author{
SANDRO RODRIGO DE BARROS \\ Michigan State University (MSU), Lansing, Estados Unidos da América \\ Melissa Mendes Caputo Vicente \\ Universidade Católica de Santos (UNISANTOS), Santos, São Paulo, Brasil
}

\begin{abstract}
Resumo: O presente ensaio propõe uma reflexão acerca da apropriação do pensamento de Paulo Freire pela vertente da pedagogia crítica anglo-saxônica, analisando genealogicamente a construção do cânone freireano no exterior. Para tanto, determinados aspectos hermenêuticos serão abordados acerca das traduções para o inglês de sua obra principal, Pedagogia do Oprimido, na tentativa de resgatar as dimensões epistêmicas de sua filosofia, sobre o tripé da ética, da dialética e da espiritualidade que nortearam a prosa de Freire.
\end{abstract}

Palavras-chave: Paulo Freire. Decolonialidade. Genealogia. Pedagogia Crítica.

\section{INTRODUÇÃO}

O presente ensaio propõe uma reflexão acerca da apropiação do pensamento de Paulo Freire pela vertente da pedagogia crítica anglo-saxônica, analisando genealogicamente a construção do cânone freireano no exterior. Certamente a reinvenção de seus conceitos pedagógicos é algo que o próprio Freire defendia como imprescindível, tanto para o desenvolvimento de suas teorias quanto para a concretização do projeto emancipador de sua proposta, dentro e fora do âmbito institucional acadêmico (FREIRE; MACEDO, 2014). Logo, tarefa a que nos dispomos aqui é registrar certos aspectos da cultura hermenêutica que envolvem descontinuidades no pensamento freireano no mercado linguístico anglo-saxão, que o construiu como um objeto-sujeito de pesquisa em caráter internacional.

A proposta genealógica que lançamos, através deste ensaio se faz relevante a partir do momento em que consideramos o papel instrumental do inglês e das traduções como dispositivos institucionais. Tais ações, em sua especificidade, moldaram, e continuam moldando, a mensagem do filósofo brasileiro mediante a ação de agendas políticas particulares vinculadas a movimentos de justiça social que veem a educação como uma ferramenta para tal objetivo.

Na conclusão deste ensaio, indagamos sobre possibilidade de um retorno decolonial à textualidade freireana, uma vez identificado o emaranhado discursivo que informa os limites da imaginação de sua pedagogia como um projeto existencial, além do âmbito institucional escolar tradicional. 


\section{PAULO FREIRE NOS ESTADOS UNIDOS}

É inegável o fato de que a obra mais conhecida de Paulo Freire, a Pedagogia do Oprimido (1970), ocupa atualmente uma posição singular nos programas de educação norte-americanos, onde a leitura do capítulo sobre o sistema bancário da educação é presença constante em diversas áreas, desde a formação de professores até os programas graduados. Porém, ao contrário do que se pensa, a caracterização da Pedagogia do Oprimido como best seller instantâneo, ao ser publicada em inglês, não condiz com a realidade da recepção da obra.

Até meados da década de 1980, o nome de Freire não era necessariamente reconhecido no universo acadêmico anglo-saxão, mesmo que as notícias positivas sobre sua campanha de letramento em Angicos (1963) tivessem alcançado países latinoamericanos vizinhos ao Brasil, antes mesmo da publicação de Pedagogia do Oprimido (escrito em 1968 e publicado, primeiramente, em espanhol). Um engajamento extensivo com os postulados filosóficos do educador brasileiro não viria a ocorrer até uma década depois da publicação em inglês, que ocorreu em 1970, antes mesmo da edição brasileira (KIRKENDALL; GOTTESMANN, 2010).

Jonathan Kozol, educador, escritor e ativista estadunidense, foi um dos primeiros intelectuais a reconhecer a relevância da Pedagogia do Oprimido fora do seu contexto brasileiro. Numa edição do The New York Times, de 1970, endossa entusiasticamente o trabalho de Freire, observando que, apesar de seu contexto latinoamericano, as teorias que Freire discute em seu livro sobre a natureza política da pedagogia - a educação bancária, a ação dialógica, o currículo deliberativo, entre outras questões - eram úteis para os projetos educacionais desenvolvidos no norte global.

A primeira visita de Paulo Freire aos Estados Unidos se deu em 1967 (FREIRE, 2014). Nessa ocasião, o educador entrou em contato com vários movimentos de base em Nova lorque e manteve contato com organizações cristãs e agências não governamentais. Em sua resenha, Kozol retrata aspectos dessa visita, reiterando que durante esse primeiro período nos Estados Unidos, Freire se absteve de qualquer envolvimento direto com políticas locais. O pedagogo preferiu focar-se em discussões relativas aos problemas da América Latina e o que poderia haver em comum entre os países ditos "subdesenvolvidos" e os problemas educacionais relacionados às graves desigualdades sociais presenciadas nos Estados Unidos.

Em sua obra Pedagogia da Esperança - um reencontro com a pedagogia do oprimido (2014, p. 142), Freire menciona que o convite da visita aos Estados Unidos teria ocorrido por sugestão do educador Ivan Illich, um padre católico romano, teólogo, filósofo e crítico social, excomungado por suas atividades políticas. Illich tomou conhecimento das experiências de alfabetização encabeçadas por Freire no Brasil e, posteriormente, no Chile.

Na sua primeira visita de 1967, Freire permaneceu em território estadunidense por uma semana, aproximadamente. Seus contatos com ativistas de base foram orquestrados, principalmente, por organizações ecumênicas - e não acadêmicas - que apresentaram o pedagogo brasileiro a ativistas locais e líderes comunitários. 
BARROS, S. R.; VICENTE, M. M. C.

Em 1969, dois anos após sua primeira viagem aos Estados Unidos, porém, Freire aceitou um cargo temporário no Centro de Estudos em Educação e Desenvolvimento da Escola de Graduação em Educação da Universidade de Harvard, em Cambridge, Massachusetts. Durante essa segunda visita, de aproximadamente um ano, Freire teve a oportunidade de estabelecer relações mais profundas com pesquisadores norteamericanos ligados aos estudos de alfabetização de adultos. A estadia em Cambridge permitiu a Freire dar continuidade às relações que tinha estabelecido com ativistas políticos na sua primeira visita. Nesse meio tempo, o pedagogo também colaborou com a tradução de uma coleção de ensaios intitulada "Ação Cultural para a Liberdade", pela Harvard Educational Review, e supervisionou a tradução para o inglês da Pedagogia do Oprimido (FREIRE, 2014).

Entretanto, apesar dessas publicações e do apadrinhamento de nomes reconhecidos no campo da educação progressista anglo-saxã - como a filósofa Sarah Maxine Greene, que organizou um painel, no final dos anos 1970, sobre o trabalho de Freire numa das reuniões anuais da American Educational Studies Association - a verdade é que poucos acadêmicos chegaram a conhecer a obra maestra do pensador brasileiro (GOTTESMAN, 2010). Em uma pesquisa a 74 revistas acadêmicas, o pesquisador norte-americano Isaac Gottesman (2010) observa que houve um atraso dramático na recepção às teorias freireanas dentro dos estudos internacionais da educação. De 1970 a 1974, são encontradas 52 referências ao autor Paulo Freire. Entre 1975 e 1979, esse número sobe para 99 . E de 1980 a 1984, encontra-se um total de 135 citações. Entre 1985 e 1989, entretanto, nota-se um salto dramático no número de referências a Freire, 232, continuando a aumentar entre 1990 e 1994 a 350.

Considerando esse crescimento exponencial no número de referências aos textos de Freire, publicados em inglês durante a década de 1970, cabe-nos perguntar aqui quais forças intelectuais poderiam ter corroborado a reputação do pedagogo brasileiro, impulsionando-o como um nome familiar em debates educacionais. Dito de outro modo, que atores específicos contribuíram para transformar o pensamento freireano em um "corpo teórico" de caráter internacional? Quais estratégias e em quais direções epistêmicas se enquadrou a mensagem freireana de educação emancipadora dos sujeitos oprimidos?

O aumento considerável no número de publicações acadêmicas na década de 1980 nos dá algumas pistas. Os intelectuais acadêmicos dessa época se inspiram nas propostas progressistas-filosóficas, plantadas por Freire, dentro do que se reconhece hoje por pedagogia crítica, um movimento de grande expressão no campo da educação e formação de professores nos Estados Unidos. O movimento surgiu, conforme observa Darder et al. (2003, p. 2), como resultado de um desejo de dar alguma forma e coerência a uma paisagem teórica de princípios, crenças e práticas radicais que contribuíram para os ideais transformadores da escolarização democrática, nos Estados Unidos, durante o século XX.

Contudo, a pedagogia crítica não foi, e segue não sendo, uma expressão singular do pensamento crítico oriundo dos postulados neomarxistas de pesquisadores alemães ligados à chamada Escola de Frankfurt, na Alemanha (FINLAYSON, 2005). Grosso modo, poderíamos afirmar que a pedagogia crítica corresponderia muito mais a uma constelação de respostas ao zeitgeist da lógica socioeconômica emergente durante os governos de Ronald Reagan e Margareth Thatcher, do que algo homogêneo. As 
premissas básicas do movimento encontraram no pensamento freireano forte ressonância ideológica, principalmente na crítica que o educador brasileiro desenvolveu sobre a educação bancária e a infiltração da lógica neoliberal na missão das escolas públicas. De fato, na década de 1980, neoconservadores mobilizaram a imagem do governo como um obstáculo ao bem-estar dos indivíduos. Por meio desse discurso antiestadista, forças conservadoras atraíram vários grupos arraigados em políticas identitárias que se sentiram seduzidos pela "teologia da prosperidade", que colocava a responsabilidade pelo bem-estar do ser humano no indivíduo e não na coletividade.

As forças neoliberais conservadoras da época em questão acreditavam que seria através da desregulamentação e dos mercados livres que as soluções para vários dilemas sociais poderiam se resolver, incluindo a própria escola pública (PETERS, 2012). A pedagogia crítica aparece, portanto, como uma resposta aos defensores do neoliberalismo. Ativistas e educadores progressistas anglo-saxões passaram a avançar com uma plataforma política diametralmente oposta aos apelos incessantes ao desinvestimento do governo na vida pública. O setor da educação, em particular, se transformou num campo de batalha ideológica, já que o desmonte da escola pública significava um ataque direto a uma organização que, historicamente, respondia aos direitos humanos de populações marginalizadas.

A educação emancipadora desenvolvida por Freire e as propostas da pedagogia crítica coincidem e divergem em vários aspectos. O objetivo dos pedagogos críticos anglo-saxões era estabelecer uma resposta precisa à reprodução ideológica do capitalismo (GIROUX, 1988). Freire, por sua vez, não obstante à crítica ao capitalismo, buscava transcender o socialismo que vários intelectuais, ligados à esquerda, também defendiam.

Conforme descreve Paiva (2000), as atividades iniciais de Freire junto ao grupo de pesquisa do Instituto Superior de Educação Brasileira (ISEB) na década de 1950, ainda que de cunho assistencialista, buscavam uma terceira via no que se refere às propostas originadas por modelos socioeconômicos capitalistas e socialistas como polos de influência política internacional.

Diferentemente do trabalho dos pedagogos críticos, porém, o projeto freireano surgiu de experiências testemunhadas na educação de adultos, dentro de uma vertente desenvolvimentista, que não incorporava, pelo menos a princípio, a escola pública no plano da alfabetização. Já o pensamento dos pedagogos críticos norte-americanos insistia, claramente, na instituição escolar como um instrumento fundamental para a promoção de mudanças sociais significativas.

Muito embora observamos que, em $A$ Educação na Cidade (1991), Freire reflete diretamente sobre o período em que atuou como Secretário de Educação da cidade de São Paulo (1989-1991), seus argumentos se enfocavam, maiormente, nas potencialidades de iniciativas de base e extensão da pedagogia como uma atividade humana ao largo de vários espaços sociais, não só os escolares. Freire se interessava pela deliberação curricular surgida a partir de relações pedagógicas que iam bem além do âmbito escolar (TORRES, 2014; SCHUGURENSKY, 2011). Suas preocupações estavam voltadas aos hábitos de pensamento característicos das hierarquias que informam o currículo escolar, tradicionalmente organizado, bem como o próprio processo social- 
pedagógico que o constitui. Em contraste, a agenda dos pedagogos críticos norteamericanos era indiscutivelmente mais ambiciosa.

De um modo geral, ainda que heterogeneamente, a pedagogia crítica buscava identificar e defender um tipo de discurso teórico que, em princípio, permitiria seus adeptos desconstruir as ideologias, presentes em sistemas institucionais, que operavam contrários aos interesses dos cidadãos.

O educador Ira Shor, com quem Freire manteve uma amizade intelectual de vários anos, afirma que o objetivo da pedagogia crítica visava facilitar aos alunos um tipo de análise que os levassem a contemplar: os hábitos de pensamento, leitura, escrita e fala que vão além do significado superficial, primeiras impressões, mitos dominantes, pronunciamentos oficiais, clichês tradicionais, sabedoria recebida e meras opiniões, para compreender o significado profundo, as causas profundas, o contexto social, a ideologia e consequências pessoais de qualquer ação, evento, objeto, processo, organização, experiência, texto, assunto, política, mídia ou discurso. (SHOR, 1992, p. 124).

Sob esse aspecto, a Pedagogia do Oprimido significava para os pedagogos críticos um exemplo concreto de uma pedagogia progressista. O texto, de certo modo, fornecia um conjunto de práticas visíveis que exemplificavam o pensamento crítico em ação, ou seja, na sua práxis cotidiana, aplicável à realidade educacional norte-americana.

Uma vez inspirados pelos postulados freireanos, vários intelectuais passaram a mobilizar-se intensamente, popularizando o pensamento freireano ao mesmo tempo em que transformaram a pedagogia crítica numa ciência de rigueur. Entre os intelectuais de maior destaque, um dos nomes mais conhecidos, Henry Giroux, relata, por exemplo, que através de publicações especializadas buscou-se dar maior visibilidade ao trabalho de mais de 60 jovens pedagogos críticos, muitos dos quais passaram a influenciar significativamente o currículo de universidades estadunidenses (GIROUX, 2011, p. 161).

Jim Bergin, renomado editor norte-americano, se tornou o patrono de Freire no mercado acadêmico anglo-saxão. O linguista Donaldo Macedo, com quem Freire manteve uma estreita relação intelectual, produziu e colaborou com várias traduções de seus textos em obras que se tornaram bastante conhecidas (FREIRE; MACEDO, 2014; FREIRE, 1985). O pesquisador Ira Shor desempenhou também um papel expressivo na divulgação inicial do pensamento freireano nos Estados Unidos, escrevendo uma série de livros dialogados que uniam, na teoria e na prática, a visão emancipatória que Freire defendia.

A afetividade intelectual que os pesquisadores da nascente pedagogia crítica sentiam por Freire inevitavelmente contribuiu para a integração de suas reinvenções como um projeto singular do pensador brasileiro. Freire se tornou um nome intercambiável com o movimento, o que repercutiu significativamente para as direções epistemológicas que foram dadas às suas obras e a maneira pela qual Freire era recebido dentro de círculos acadêmicos que o liam exclusivamente em inglês.

\section{A TRADUÇÃO ACADÊMICA E A PROBLEMÁTICA DO CONHECIMENTO FREIREANO}

Ao caracterizar o pensamento de Freire, vários pedagogos críticos tecem certas observações sobre o trabalho do educador brasileiro que merecem nossa atenção. Por exemplo, Georgios Grollios et al. (2015, p. 8, grifo nosso) afirmam que: 


\begin{abstract}
Para desenvolver as ferramentas de que precisava para refletir criticamente e se engajar na práxis, Freire escolheu saciar sua curiosidade epistemológica lendo pensadores e filósofos ocidentais criticamente importantes. Sem essa leitura, sua compaixão pelos oprimidos poderia ter se truncado na indignação ou na raiva, sem os canais intelectuais para criar uma pedagogia devidamente informada tanto pela emoção quanto pela cognição, uma realidade que Freire dicotomizou.
\end{abstract}

O que nos impressiona na citação acima é como esses críticos expressam categoricamente que se Freire não tivesse estado em contato com "filósofos ocidentais importantes", sua atividade intelectual certamente teria "mergulhado na indignação e na raiva". Dentro desta perspectiva, emergem duas orientações interpretativas que gostaríamos de assinalar pelo modo em que direcionam o pensamento freireano.

A primeira orientação se relaciona ao silêncio sobre o sincretismo deste pensamento na sua veia antropofágica. A referência à dependência de Freire do pensamento iluminista europeu para chegar a uma conclusão acerca do universo e dos problemas que caracterizam uma sociedade acusa uma sujeição do intelectual póscolonial à racionalidade da metrópole iluminista que, supostamente, serviria de alicerce da razão.

A segunda orientação se apoia numa perspectiva racionalista do que significa pensar criticamente. Nela, percebemos uma aparente expressão do déficit intelectual do/a educando/a, que necessita que o intelectual esclarecido o/a conduza a "pensar corretamente." Giroux (2011) chega a afirmar que Freire dicotomizou emoção e cognição para alcançar uma "clareza de pensamento" que poderia tornar a educação um projeto viável de emancipação intelectual das formas materiais e ideológicas de opressão. Alguns leitores mais familiarizados com o conjunto da obra Freire, obviamente, reconhecerão que tal divórcio entre razão e emoção estaria em conflito com a visão de mundo que o educador brasileiro defendia. Parece sugerir que educandos e educandas desconhecem seu mundo, sua realidade, a menos que o intelectual interceda por eles e os "faça" enxergar uma realidade desconhecida. Contrário a essa perspectiva, Freire denunciou, ao longo de seus trabalhos, que tal lógica dicotômica certamente levaria qualquer projeto de educação emancipatória ao fracasso.

Logo, percebemos aqui uma diferença de posicionamentos específica com respeito ao princípio da educação como uma prática da liberdade. Certas vertentes da pedagogia crítica dão a entender que o pensamento freireano se apoia em intelectuais com "disposições críticas" que "iluminam" o pensamento do povo. Contudo, desde a Pedagogia do Oprimido, Freire admite que o trabalho dos educadores está sempre relacionado a como aprender com educandos/as, o que eles/as entendem por democracia e o que desejam dela.

$\mathrm{Na}$ práxis, esse entendimento nos leva a uma constante redefinição do significado da democracia pela pedagogia, como um projeto futurístico permanente de negociações constantes. Os critérios que determinam o mundo, portanto, se dão entre jogos de posições, em que o objetivo é evitar que o sonho do oprimido se conforme ao que o opressor tenha sonhado para si. Como o próprio Freire afirma, a tarefa 
humanística e histórica dos oprimidos é “libertar-se a si e aos opressores. Estes, que oprimem, exploram e violentam, em razão de seu poder, não podem ter, neste poder, a força de libertação dos oprimidos nem de si mesmos" (2014, p. 30-31).

Se faz necessário aclarar ainda que, embora Freire tenha se referido em múltiplas ocasiões ao educador ou educadora crítica, ele nunca se referiu a suas atividades como "pedagogia crítica". Ao longo de seus livros dialogados, muitos deles escritos em parceria com intelectuais ligados ao movimento nos Estados Unidos, Freire descreve sua filosofia enquanto ação dialógica ou pedagogia libertadora.

Esse vocabulário poderia ter sido adotado, propositadamente, para distanciarse do trabalho relacionado, mas diferente, dos pedagogos críticos norte-americanos. Se por um lado, os pedagogos críticos coincidiam com Freire na mobilização da educação para o combate aos mitos de neutralidade, objetividade e imparcialidade, oriundos da educação bancária; por outro lado, o projeto freireano se relacionava a movimentos populares de educação não ligados, necessariamente, a instituições.

Entretanto, é no tratamento dispensado à autoridade pedagógica que encontramos outra divergência relacionada às interpretações mainstream da pedagogia crítica, que influenciaram a direção epistemológica que se deu ao pensamento freireano no exterior. A pedagogia crítica favorece a importância do papel do intelectual tradicional, orgânico, tal como o descrevia Gramsci (2011), quem lidera e orienta os educandos (povo) para que atinjam um "nível superior" de criticidade, a caracterização discursiva convencional dos professores como "agentes transformadores" (GIROUX, 2011).

Contudo, as teorias freireanas, ao longo do seu desenvolvimento, não defendiam, necessariamente, a posição do professorado como se essa classe estivesse incumbida de liderar movimentos de justiça social, principalmente pelo risco que tal posicionamento decorre. A ação educadora que se serve das mesmas armas de dominação, dizia Freire (2019, p. 77), seja a propaganda dos slogans, ou dos "depósitos", certamente se converteria numa imagem especular opressiva daquilo que combate. Ou seja, em critérios de liderança, Freire parece sugerir uma imagem de educadoreseducandos como atores vulneráveis no universo epistêmico dos educandoseducadores. O pedagogo teorizou extensivamente sobre como a autoridade de um professor ou professora emana, de forma mais autêntica, a partir da curiosidade da classe pelas ações e modo de pensar de seus alunos.

Essa ideia se apresenta com nitidez em Professora sim, Tia Não (1993), no qual Freire afirma que os educadores nunca podem saber com exatidão o que é melhor para seus alunos. É através de uma confiança radical na capacidade dos educandos/as, enquanto ao processo de sua respectiva emancipação intelectual, que os/as mesmos/as cumpririam seu papel profissional. Por exemplo, ao discorrer sobre disciplina e autoridade pedagógica Freire observa que:

Para que haja disciplina é preciso que a liberdade não apenas tenha o direito mas o exerça de dizer "não" ao que se lhe propõe como a verdade e o certo. A liberdade precisa aprender a afirmar negando, não por puro negar, mas como critério de certeza. É neste movimento de ida e volta que a liberdade termina por internalizar a autoridade e se torna uma liberdade com autoridade somente como, enquanto autoridade, respeita a liberdade. A 


\begin{abstract}
responsabilidade que temos, enquanto seres sociais e históricos, portadores de uma subjetividade que joga papel importante na História, no processo deste movimento contraditório entre autoridade e liberdade, é de indiscutível importância. Responsabilidade política, social, pedagógica, ética, estética, científica. (FREIRE, 2015, p. 77).
\end{abstract}

As diferenças entre Freire e as linhas epistemológicas da pedagogia crítica, que o constituem no exterior, merecem ainda um questionamento que, de certa forma, ecoa a pergunta incessante elaborada por Gayatri Spivak, em 1988, em seu ensaio canônico "Can the Subaltern Speak?". Por meio desta pergunta, Spivak não alude somente à questão da ação mediadora da alteridade subalterna por interlocutores bemintencionados localizados no chamado "norte global". A autora questiona a própria natureza da língua como um instrumento político. Ou seja, se o subalterno não fala nem produz conhecimento acadêmico num código específico de poder, quem o escutará?

Sob esse aspecto, vale a pena aproximar-nos de algumas questões tangentes das traduções do pensamento freireano na língua inglesa. Por exemplo, na Pedagogia do Oprimido, Freire (2019, p. 73) escreve:

Que o pensar do educador somente ganha autenticidade na autenticidade do pensar dos educandos, mediatizados ambos pela realidade, portanto, na intercomunicação. Por isto, o pensar daquele não pode ser um pensar para estes nem a estes impostos. Daí que não deva ser um pensar no isolamento, na torre de marfim, mas na e pela comunicação, em torno, repitamos, de uma realidade.

Porém, a versão de Myra Ramos em inglês deixa transparecer uma mensagem diferente, certamente mais austera:

The teacher's thinking is authenticated only by the authenticity of the students' thinking. The teacher cannot think for her students, nor can she impose her thought on them. Authentic thinking, thinking that is concerned about reality, does not take place in ivory tower isolation, but only in communication. If it is true that thought has meaning only when generated by action upon the world, the subordination of students to teachers becomes impossible (FREIRE, 2014, p. 77).

Observamos na citação acima que apesar da grande dificuldade que gera a versão em inglês para a compreensão de um pensamento complexo até no original em português, se ausenta uma orientação epistêmica que alude à realidade como uma chave mediadora do pensamento. Expressando-nos mais criticamente, vemos no original que Freire não descreve o que é ou não o pensamento autêntico como uma categoria epistêmica e ontológica imutável; ele elabora sobre o tema de "pensar autenticamente" como resultado da ação dialógica entre professores e alunos. Sendo assim, o educador não impõe o pensamento autêntico como uma verdade soberana, 
conforme a tradução inglesa sugere. Freire defende o inédito viável como atitude pedagógica autêntica na honestidade dialógica.

Portanto, se por um lado a pedagogia crítica construiu possibilidades para a proliferação da obra de Freire no exterior, principalmente através da tradução de suas obras ao inglês, por outro tal cultura hermenêutica formada a partir de leituras disciplinares alteraram aspectos significativos de sua obra. Tais reorientações não passaram despercebidas entre os próprios acadêmicos norte-americanos. O pesquisador e filósofo da educação Samuel D. Rocha, por exemplo, afirma que qualquer leitura de Freire em português se faz imprescindível, já que a tradução ao inglês é "lamentavelmente inadequada para o uso acadêmico" (2020, p. 29).

O leitor bilíngue certamente notará que as traduções da obra de Freire para o inglês conotam uma tonalidade marcadamente áspera, onde desaparece o caráter afável e poético da sua linguagem original. Isso, argumentamos, dificulta um entendimento antropofágico da sua prosa, em que as tensões características do universo pós-colonial brasileiro se exibem abertamente pelas contradições apresentadas de um universo cindido, de seres interpelados pela escassez e o desencantamento de discursos neoliberais que ressaltam a meritocracia como justiça. Resultantemente, o discurso anglo-saxão ignora as possibilidades que nascem "dos cruzamentos e da diversidade como poética/política na emergência de novos seres e na luta pelo reencantamento do mundo" (RUFINO, 2019 p. 6).

A linguagem marcadamente antropofágica e repleta de neologismos indubitavelmente desafia qualquer transposição do ideário freireano a outros contextos e linguagens. Na prática, a escrita de Freire apresenta modos criativos de descrever a qualidade transitiva dos papéis pedagógicos e fenômenos associados à educação no contraponto entre a escola e a comunidade. O próprio termo "educando" - da forma nominalizada do verbo educar no gerúndio - constitui uma descrição neológica marcante pela qual Freire designa os alunos como "sujeitos educadores" e não meramente como agentes passivos. A falta de notas explicativas acerca de tais aspectos sociolinguísticos da escrita freireana omite, em inglês, a tentativa consciente por parte do autor de intervir e criticar o discurso do professorado, pela própria linguagem, como um método criador do inédito viável que defendia. Conforme observa Simões (2006), os neologismos da prosa freireana respondem precisamente a uma necessidade expressiva no pedagogo, sentindo-se limitado pelo vocabulário da ciência convencional, buscou uma leitura mais aprofundada da realidade da educação, como um projeto humanizador, articulando sua transformação por meio da reinvenção estética do português, como visto na prosa modernista.

O enquadramento da pedagogia crítica, em suas traduções epistêmicas, tende a omitir ou diminuir também a importância da espiritualidade como elemento basilar do universo conceitual freireano. As discussões que se geraram em torno de sua teoria ignoram uma bagagem teológica vital para a práxis humanizadora, tal como Freire nos deixa entender.

É certo que o próprio Freire reconheceu que não se sentia à vontade falando de sua fé a menos que falasse também da mesma como uma opção política, utópica e reveladora de seus sonhos pedagógicos. O educador afirmou categoricamente em várias ocasiões que ao falar de Deus, sempre admitia sua importância como um princípio 
"na luta pela superação da realidade opressora e pela construção de uma sociedade menos feia, menos malvada, mais humana" (FREIRE, 2015, p. 85).

Vejamos, então, alguns aspectos paródicos da textualidade freireana que, ao nosso ver, resgatam o humanismo crítico de Freire ao aproximar-se da problemática em torno da educação enquanto um projeto emancipatório.

A "conversão ao outro", sobre a que discursa Freire na sua Pedagogia do Oprimido (2007, p. 147), por exemplo, espelha-se muito em Mateus, 7:12, especificamente numa passagem na qual o apóstolo afirma: "Então, em tudo, faça aos outros o que você gostaria que fizessem a você, pois isso resume a Lei e os Profetas." Falar de conversão, no contexto da conscientização freireana, é falar de uma alteração radical do próprio sistema de crenças sobre o que as pedagogias podem fazer por si e, efetivamente, pelos outros, se pensamos em pedagogia dentro ou fora dos domínios da educação institucionalizada.

Outro paralelo entre o discurso de Freire e o catecismo teológico evangélico pode ainda ser traçado sem muito esforço quando nos sintonizamos com o estilo epistolar freireano. Em Coríntios, 5:17, encontramos a seguinte passagem: "Portanto, se alguém está em Cristo, é nova criação. As coisas antigas já passaram; eis que surgiram coisas novas! Tudo isso provém de Deus, que nos reconciliou consigo mesmo por meio de Cristo e nos deu o ministério da reconciliação." (BÍBLIA, 2008).

Em contrapartida, na Pedagogia do Oprimido, Freire discursa sobre a "conversão ao povo", que, segundo o educador, exige um "renascimento profundo" do ser humano. Ao desenvolver essa ideia, Freire nota que aqueles que passam por tal processo "assumem uma nova existência," sendo que ninguém mais permanece como era (2014, p. 74-75).

Portanto, seria difícil argumentar, como sugere a pedagogia crítica, que a análise freireana foca-se exclusivamente nas condições materiais que transformam atitudes e relações humanas dentro da sociedade. A educação libertadora que Freire parece ter defendido busca, num pensamento espiritual, e não religioso, um sentido de libertação de formas particulares de pensamento, condicionadas por uma época particular.

Se por um lado Freire integra em suas análises a construção sociopolítica da religião sob uma ótica materialista, observando, por exemplo, que as falsas noções de Deus fomentaram o fatalismo nos povos oprimidos, a pedagogia do oprimido vai muito além de Marx e o materialismo excessivo de certas correntes da pedagogia crítica (e.g., GIROUX, 2011; KINCHELOE, 2008).

Para Freire, o divino, pensado a partir da práxis, nos convida a recriar o mundo como um ato de libertação de hábitos intelectuais que nos coloca em situações de impasse. Neste sentido, a incompreensão da presença do cristianismo dentro da dinâmica teórica freireana se apresenta como um mistério para muitos críticos marxistas, no exterior, que desconhecem a veia antropofágica de sua dialética (c.f. MCLAREN, 2015).

Como o próprio Freire reconhece, as marcas de sua formação cristã são rejeitadas por várias leituras sectaristas e autoritárias do humanismo de sua obra (2003/1996, p. 102). Em À sombra desta mangueira, admite a importância de sua fé ao 
afirmar que: "Minha fé me sustenta, me estimula, me desafia; jamais me disse: para, acomoda-te, as coisas são assim porque não podem ser de maneira diferente" (FREIRE, 1995 , p. 85). Sem tal base cristã-humanista, as traduções e interpretações que se fazem da mensagem pedagógica de Freire arriscam perder de vista uma visão da educação como uma "oferta" de um corpo encarnado para o outro na busca constante de transcender o necrofilismo da realidade que se apresenta como um fatalismo herdado da mentalidade colonial (FREIRE, 2007; 1970, p. 50).

Ao contrário do que muitos argumentam sobre o significado da ação dialógica para tal transcendência crítica à realidade necrofílica do conhecimento (e.g., SHOR, 1992), Freire não sugere o modelo socrático, no qual o educador, através do questionamento, manipula o corpo discente até que este concorde com o que o docente predica como uma via educativa. $O$ diálogo na base educativa freireana serve como uma ferramenta problematizadora do mundo, já que a linguagem humana é, em última análise, o que cria e recria a realidade (FREIRE e MACEDO, 2014). Ou seja, ensinar o aluno a "pensar corretamente" não significa o ponto de partida nem de chegada enquanto um objetivo da educação. O diálogo representa o próprio problema da educação, bem como a solução para ela, seja imaginada institucionalmente ou não.

Por essa razão, quando lemos em inglês que se humanizar significa "tornar-se plenamente humano" (to be fully human), em vez de "ser mais," como Freire originalmente escreve, percebemos o quanto de sua educação emancipatória se perde na transposição de sua definição de ser humano como um projeto inacabado, sempre em andamento, vocacionalmente orientado a ser mais, e não um déficit a ser superado.

Logo, cabe-nos perguntar aqui se as críticas que Freire eventualmente recebe não partiriam de uma falta de reconhecimento da especificidade semântica de sua obra, que o julga como uma voz masculinista/racionalista e antropocêntrica, oriunda de um pensamento neocolonial iluminista, em que o ser humano é pensado como o centro do universo, e não, como um produto das relações que mantêm com o mundo (ELLSWORTH, 1989; MACEDO et al., 1997).

Afinal, a luta por uma educação intelectualmente emancipatória, na base freireana, tem como objetivo o reconhecimento do direito universal à diferença, dialeticamente sublimando tudo aquilo que constrange a imaginação e a capacidade criativa do ser.

Essa dialética se percebe até mesmo na operação que Freire faz de categorias como opressor e oprimido. A dialética como método reflexivo estimula a reavaliação das relações pedagógicas pelas quais os/as educadores/as e os/as educandos/as mantêm-se presos a conceitos e a um fatalismo perene. Isso inclui a opressão no sentido teológico.

De qualquer forma, Freire considera que a ação educativa que informa o pensamento disciplinar conceitual surge como um efeito da ação da consciência humana no seu modo de inter-relacionar-se, além das escolhas que determinam os modos em que o mundo pode ser pensado e repensado (FOUCAULT, 2012). Por isso, o educador insiste no princípio da pedagogia como uma prática comunicativa abrangente, a práxis de uma democracia fundamentalmente radical.

Não se trata de pensar em democracia como uma luta identitária ou de classes apenas. A educação emancipadora requer o reconhecimento a priori de que as pessoas são igualmente capazes de direcionar seu intelecto para a formação de suas próprias opiniões, manifestando sua diferença de forma radical, ou seja, autêntica. 


\section{A MODO DE CONCLUSÃO: VOLTAR A FREIRE}

Como observa Carlos Alberto Torres (2014, p. 26), a obra de Freire corresponde a uma amálgama teórico de considerável alcance, no qual - em seus elementos mais úteis e significativos - inclinações filosóficas diferentes se complementam em alguns casos e se confrontam e se opõem em outros. $\mathrm{O}$ existencialismo, a fenomenologia, o marxismo e dialética hegeliana, junto a movimentos católicos de base, inspirados pelo neotomismo, desempenharam um papel fundamental na construção de uma teoria singular e abertamente antropofágica no seu caráter aglutinador e sincrético.

Até certo ponto, seria de se esperar que qualquer leitura que desconheça o universo antropofágico da escritura freireana perca de vista a atitude ambivalente frente ao que "vêm de fora." Certamente, até mesmo o tradutor mais talentoso teria que reconhecer a dificuldade de traduzir a prosa freireana a outros idiomas. No entanto, por melhor que seja qualquer tradução, a leitura constitui um simulacro e, sendo assim, as relações de poder que mantém uma língua dita "franca" sempre merecem consideração especial, principalmente em traduções intelectuais oriundas de universos pensados como subalternos.

No caso que aqui exploramos da recepção de Freire pela pedagogia crítica, a justaposição da obra do pedagogo dentro do ímpeto quase-positivista do movimento pode até resultar interessante. Contudo, tal justaposição tende a desconsiderar a dimensão semântica-espiritual do pensamento de Freire no seu caráter antropofágico, reinventando-o além dos pontos referenciais que determinam sua essência e que poderiam servir como um caminho de volta para a sua desinvenção.

Ao nosso ver, a necessidade do momento está relacionada ao desacoplamento do discurso freireano do aparato enunciativo que o sustenta como um filósofo "universal". A união discursiva de Freire, como um pedagogo crítico à maneira norteamericana, gera uma certa detração pendular em que a argumentação sobre a potencialidade de suas ideias permanece presa a extremidades ora da esquerda ou da direita. Além dessas posições, o pêndulo freireano não consegue se mover (BALDACCHINO, 2021).

A prática epistêmica de desacoplar Freire da pedagogia crítica - um exercício que Mignolo (2011) define como uma opção necessária para a decolonização dos saberes - não pode querer corrigir "falhas" nas várias reinterpretações que se fazem a partir de sua mensagem pedagógica. Isto seria repetir uma imagem especular arrogante do objeto da crítica que faz o educador: o conhecimento tratado como um dogma. $\mathrm{O}$ que se pode buscar de novo, no exercício da opção decolonial das traduções freireanas, é dar continuidade à uma ação dialógica para desinventar e reconstituir suas ideias.

Nesta perspectiva, a negação da razão como um instrumento dogmático que inventa certezas sobre a natureza humana constitui uma atitude epistêmica para a desinvenção e reconstituição do corpo teórico freireano, após suas exaustivas leituras internacionais.

Reconhecer Paulo Freire na sua alteridade constitui, de fato, tarefa imprescindível para um retorno às suas obras com um novo olhar que não perde de vista as dúvidas que sempre nos motivam a ser mais ao encontrar-nos com as suas 
BARROS, S. R.; VICENTE, M. M. C.

ideias, ainda relevantes para a realização de projetos educacionais voltados à equidade e justiça social.

Artigo recebido em: 01/04/2021

Aprovado para publicação em: 29/06/2021

POWER, POLITICS, AND TRANSLATION: NOTES FOR A GENEALOGY OF PAULO FREIRE'S PHILOSOPHY ABROAD

ABSTRACT: This essay proposes a reflection on the appropriation of Paulo Freire's thought by the Anglo-Saxon branch of critical pedagogy, genealogically analyzing the construction of the Freirean canon abroad. To this end, certain hermeneutical aspects will be addressed concerning the English translations of his main work, Pedagogy of the Oppressed, in an attempt to rescue the epistemic dimensions of his philosophy, on the tripod of ethics, dialectics and spirituality that guided Freire's writing.

KEYWORDS: Paulo Freire. Decolonialization. Genealogy. Critical Pedagogy.

PODER, POLITICA Y TRADUCCIÓN: APUNTES PARA UNA GENEALOGÍA DEL PENSAMIENTO FREIREANO EN EL EXTRANJERO

RESUMEN: Este ensayo propone una reflexión sobre la apropiación del pensamiento de Paulo Freire por parte de la rama de la pedagogía crítica anglosajona, analizando genealógicamente la construcción del canon freireano en el exterior. Por lo tanto, se abordarán ciertos aspectos hermenéuticos sobre las traducciones al inglés de su obra principal, Pedagogía del Oprimido, en un intento por rescatar las dimensiones epistémicas de su filosofía, sobre el trípode de la ética, la dialéctica y la espiritualidad que guiaron la prosa de Freire.

PALABRAS CLAVE: Paulo Freire. Decolonialidad. Genealogía. Pedagogía Crítica.

\section{REFERÊNCIAS BIBLIOGRÁFICAS}

BALDACCHINO, John. Separated by a common heterodoxy: Illich, Freire and the perilous spell of radical canonicity. Manuscrito não publicado, 2021.

BARROS, Sandro. Paulo Freire in a Hall of Mirrors. Educational Theory, 70, p. 151-169, 2020. Disponível em: <https://doi.org/10.1111/edth.12413>. Acesso em: 27 ago. 2021.

BíBLIA, Coríntios. In: BÍBLIA. Sagrada Bíblia Católica: Antigo e Novo Testamentos. São Paulo: Sociedade Bíblica de Aparecida, 2008. 
Poder, política e tradução: notas para uma genealogia do pensamento...

DARDER, Antonia et al. The Critical Pedagogy Reader. New York: The RoutledgeFalmer, 2003.

ELLSWORTH, Elizabeth. Why Doesn't This Feel Empowering? Working Through the Repressive Myths of Critical Pedagogy. Harvard Educational Review 297-325: Cambridge, $1989 . \quad$ Disponível em: <https://doi.org/10.17763/haer.59.3.058342114k266250>. Acesso em: 27 jul. 2021.

FINLAYSON, James. Habermas: A Very Short Introduction. New York, NY: Oxford University Press, 2005.

FOUCAULT, Michel. A arqueologia do saber. Rio de Janeiro: Forense Universitária, 2012.

FREIRE, Paulo; FREIRE, Ana Maria A. Cartas a Cristina: reflexões sobre minha vida e minha práxis. São Paulo: Editora UNESP, 2003.

FREIRE, Paulo. A educação na cidade. São Paulo: Cortez, 1991.

FREIRE, Paulo. À sombra desta mangueira. Rio de Janeiro: Paz e Terra, 2015.

FREIRE, Paulo. Ação cultural para a liberdade. 5 ed. Rio de Janeiro: Paz e Terra, 1981.

FREIRE, Paulo. Pedagogia da Esperança: um reencontro com a Pedagogia do Oprimido. Rio de Janeiro: Paz e Terra, 2014.

FREIRE, Paulo. Pedagogia do Oprimido. Rio de Janeiro: Paz e Terra, 2007 - 2014 - 2019.

FREIRE, Paulo. Pedagogy of the Oppressed. Londres: Bloomsbury Publishing, 2014.

FREIRE, Paulo. Professora, sim; Tia, não. Cartas a quem ousa ensinar. Rio de Janeiro: Paz e Terra, 2015.

FREIRE, Paulo. The Politics of Education: Culture, Power, and Liberation. Connecticut: Bergin \& Garvey, 1985.

FREIRE, Paulo; MACEDO, Donaldo. Alfabetização: leitura do mundo, leitura da palavra. Rio de Janeiro: Paz e Terra, 2014.

GIROUX, Henry. On Critical Pedagogy. Londres: Bloomsbury Publishing, 2011.

GIROUX, Henry. Teachers as intellectuals: toward a critical pedagogy of learning. Connecticut: Bergin \& Garvey, 1988.

GOTTESMAN, Isaac. Sitting in the Waiting Room: Paulo Freire and the Critical Turn in 
BARROS, S. R.; VICENTE, M. M. C.

the Field of Education. Educational Studies: A Journal of the American Educational Studies Association, v. 46, n. 4, 2010. Disponível em: <https://philpapers.org/rec/GOTSIT>. Acesso em: 26 jul. 2021.

GREEN, Eliot. What are the most-cited publications in the social sciences? Disponível em: $\quad<$ https://blogs.Ise.ac.uk/impactofsocialsciences/2016/05/12/what-are-the-mostcited-publications-in-the-social-sciences-according-to-google-scholar/> Acesso em: 26 jul. 2021.

GROLLIOS, Georgios et al. Paulo Freire and the Curriculum. Oxford: Taylor \& Francis, 2015.

KINCHELOE, Joe L. Critical Pedagogy Primer. Switzerland: Peter Lang Publishing, 2008.

KIRKENDALL, Andrew J. Paulo Freire \& the Cold War Politics of Literacy. North Carolina: The University of North Carolina Press, 2010.

KOZOL, Jonathan. Coming Up for Freire. The New York Review. Disponível em: <https://www.nybooks.com/articles/1970/10/22/coming-up-for-freire/>. Acesso em26, jul, 2021.

MACEDO, Donaldo et al. Mentoring the Mentor: A Critical Dialogue with Paulo Freire. Switzerland: Peter Lang Publishing, 1997.

MCLAREN, Peter. Pedagogy of Insurrection: From Resurrection to Revolution. Switzerland: Peter Lang Publishing, 2015.

MIGNOLO, Walter. The Darker Side of Western Modernity Global Futures, Decolonial Options. North Carolina: Duke University Press, 2011.

PAIVA, Vanilda Pereira. Paulo Freire e o nacionalismo-desenvolvimentista. Rio de Janeiro: Editora Civilização Brasileira, 1980.

PETERS, Michael Adrian. Neoliberalism, Education and the Crisis of Western Capitalism. Policy Futures in Education, v. 10, n. 2, 2012. Disponível em: $<$ https://journals.sagepub.com/doi/pdf/10.2304/pfie.2012.10.2.134>. Acesso em 26 jul. 2021.

ROCHA, Samuel D. The Syllabus as Curriculum: A Reconceptualist Approach. Oxford: Taylor \& Francis, 2020.

RUFINO, Luiz. Pedagogia das Encruzilhadas. Rio de Janeiro: Mórula Editorial, 2019.

SCHUGURENSKY, Daniel. Paulo Freire. London: Bloomsbury Publishing, 2011.

SHOR, Ira. Empowering Education: Critical Teaching for Social Change. Chicago: 
Poder, política e tradução: notas para uma genealogia do pensamento...

Chicago University Press, 1992.

SIMÕES, Sérgio Lourenço. Pedagogia do neologismo: diálogos sintáticos-semânticos na obra de Paulo Freire. 2006. 200 f. Dissertação (Mestrado em Educação) - Universidade Nove de Julho, São Paulo, 2006.

SPIVAK, Gayatri. Can the Subaltern Speak? In: Marxism and the Interpretation of Culture. Illinois: Illinois University Press, 1988, p. 271-313.

TORRES, Carlos Alberto. First Freire: Early Writings in Social Justice Education. New York: Teachers College Press, 2014.

SANDRO BARROS: Michigan State University, Assistant Professor, Department of Teacher Education, Ph.D., Romance Languages and Literatures, University of Cincinnati. Lansing, Michigan, USA.

Orcid: https://orcid.org/0000-0002-5056-052X

E-mail: barross1@msu.edu

Melissa Mendes Caputo Vicente: Universidade Católica de Santos, Centro de Ciências da Educação e Comunicação (CCEC), docente dos cursos de História e Pedagogia. Santos, São Paulo, Brasil.

Orcid: https://orcid.org/0000-0002-6456-0133

E-mail:melissa.vicente@unisantos.br

Este periódico utiliza a licença Creative Commons Attribution 3.0, para periódicos de acesso aberto (Open Archives Initiative - OAI). 